\title{
Study on Characteristics of Teaching Language at Information Age and Application Recommendations
}

\author{
Jin $\mathrm{He}^{1}$, Hongchong Zhang $^{2}$ \\ ${ }^{1}$ School of Electrical Engineering, Chongqing Vocational Institute of Engineering, Chongqing, \\ 400037, China \\ ${ }^{2}$ Department of Party Committee Propaganda, Chongqing Vocational Institute of Engineering, \\ Chongqing, 400037, China
}

Keywords: Information teaching, Teaching language, Characteristics, Application.

\begin{abstract}
The language of instruction is an important carrier when teachers teaching them. With the change in the information age of Teaching Media and ecological environment, the language is also changing, these changes to enhance classroom teaching, students learning initiative training, teaching efficiency, has an important influence. How proficient in teaching the language of instruction in the information age, we propose teachers should be in the language combinations presented to the "green" oriented; a reasonable trade-off in accordance with the teaching needs of each factor; according to the different stages of a reasonable set of teaching; Note that the effective combination of various languages, focused and structured so that students teaching psychological expectations.
\end{abstract}

\section{Introduction}

With the advent of the information age, multimedia and network technology has been introduced into the classroom, teaching media and teaching ecological environment has undergone tremendous changes, these changes to the language of instruction have had a significant impact, and the use of the language of instruction of a direct impact on classroom teaching effect improved. Soviet educator Sukhomlinski has pointed out that "the language teacher training determine to a great extent on the students' mental efficiency in the classroom." [1] due to changes in the information age of Teaching Media and ecological environment, teachers need to follow the requirements of the curriculum, the rational use of a variety of teaching languages, constantly motivating psychological students' classroom learning, allowing students to learn while learning to become active in the process of classroom knowledge of the recipient, so that students better grasp of knowledge improve the quality of classroom teaching teachers. In order for teachers to better understand and skilled use of the language of instruction and enhance classroom teaching, research and analysis author points out the changes of the Information Age MOI, and these characteristics are given information age teachers to enhance classroom teaching and skilled use of language teaching some suggestions.

MOI has defined a narrow and broad, narrow spoken language of instruction refers only to teachers in the classroom activities used, although this definition clearly uses the principal language of instruction, but only point out a single carrier language of instruction, and Speaking just a, in addition, there are written language, audio language of instruction, and even image language. So, broadly speaking, the language spoken not only teachers in the classroom activities for use, including multiple languages written language teachers in the teaching activities used, audio language, images, language, etc., which in the teaching process engage each other, the integrated use of language constitutes a form of teaching tools and support information transfer, namely the language of instruction. It is worth noting that, due to the language of instruction on the concept of generalized contains narrow teaching language, the language of instruction is studied in this paper refers to the broad language of instruction. 


\section{Characteristics of teaching language at Information Age}

With the advent of the information age means teaching, teaching activities, the language is changing. These changes, for enhancing the effectiveness of classroom teaching, students learning initiative training, teaching efficiency, have a significant impact, and even affect the normal development of teaching and learning activities to some extent. Therefore, language teaching research and study, to be from the characteristic of the information age to start teaching language.

\section{Objective changes of language}

The existence of diversified forms of teaching language

Teachers' oral language and a variety of electro-acoustic media language constitute a diverse sound language. A variety of print media, pictures, videos, and a variety of media constitute the silent language diversity. Due to the use of languages may be combined so that the language of instruction in the information age is more vivid than traditional teaching language, image, visual, appeal stronger.

The carrying space and time of teaching language more open

With the development of computer network technology, network teaching has been greatly developed, the language is no longer just stay in the traditional classroom teaching, but as the migration of teaching places and migration occurs; time is no longer adhere to the school top class and more open. In addition, the development of virtual learning as produce such as Mu class also gives new space significance.

\section{Constantly enrich the connotation of teaching language}

In the information age, teachers in addition to the use of spoken language, body language, teaching language, but also began to try to use the situation teaching to carry out teaching activities, teachers try to use music creation in the context of teaching, role playing and other forms of teaching activities, which to some extent, enrich the connotation of teaching language. Through the creation of music, role-playing and other situational teaching methods, students can love teaching language, entertaining, access to knowledge, to enhance the effect of classroom teaching.

\section{Practical change of language application}

\section{Presentation of language teaching by telling tends interpretative}

Traditional teaching language teacher tells or verbal description based, and in the whole era of mass media, teachers can make use of text, sound, pictures, video, animation and other forms of all media languages to tell and elucidation of the teaching material, so as to enhance the classroom effect. Teachers and students in teaching and learning process, teachers found to change the functions, performance is an important way of expression to speak the language of instruction by a talk tends illustrative, since the teachers just teaching content of the issues, concepts, materials targeted explanation, analysis and description, and about reducing the frequency of use descriptive language, making use of the practice of teaching language changed.

Interactive language is given praise

At information age, advanced educational philosophy requires teachers to shift from knowledge to students who pass the organizers, participants, designers, coordinators, facilitators, students become partners. Modern educational technologies (especially computer multimedia technology and network technology) to introduce the teaching, some network communication tools such as: the emergence and development BBS, QQ, Email, microblogging, letters and other emerging media, provide a more interactive and students a wide range of platform. Thus, teaching interactive, two-way dynamic become the main features of classroom teaching language.

The impact of teaching language on teaching effect is more significant

Teaching language is an important tool to impart knowledge, wisdom, inspiration, and exchange of students. In the information age, the impact of teaching language teaching effect is more significant, showing the correct use of language teaching can effectively narrow the psychological distance with 
students, so that students in the teaching activities are no longer passive recipients of knowledge, but actively active teachers impart knowledge to comprehend, produce benign interactive teaching to enhance classroom teaching.

Advantages and disadvantages of the current language use

The use of the language of instruction is not only the most basic teaching skills of teachers, but also an art. In the teaching activities of the information age, teachers regulate the use of the language of instruction, so that students in the classroom psychological identity, for active learning; and does not regulate the use of teaching the language, it will make the Class repulsion psychological impact learning initiative.

The main advantage of the current teaching of language use: (1) the visual image, abstract to the concrete, to help students understand and learn. (2) Graphic audio-visual and Mao, multi-sensory stimulation can mobilize the students' interest in learning. (3) Can be an effective model dynamic process, effectively showing the important and difficult teaching. (4) Immediacy and interactivity significantly enhanced to enhance the sense of participation of students, teachers and teaching conducive to interaction. (5) Knowledge can be effectively mapped by the virtual space to real teaching activities so that the knowledge and vivid three-dimensional, so proud of things primitive reproduction. (6) Keep repeating, overcome forgotten, and enhance memory. (7) Targeted to meet the various levels of students' needs. (8) Sea quantization information, which can effectively save space and time to a certain extent, improve teaching efficiency.

The main drawback of the current teaching of language use: (1) the use of multimedia restrictive environment. (2) Cause a degree of influence on students' health will be. (3) Lack of emotional education effect. (4) Requires that teachers have higher media literacy, difficult to master and control to teachers.

Teaching language use it properly, a direct impact on teachers' professional identity and to enhance the positive initiative to improve student learning, so, in the information age, teachers should attach great importance to the use of language teaching, enhance the effect of classroom teaching.

\section{Suggestions on teaching language use at Information Age}

In the information age, teachers in the process of using the language of instruction should adhere to the people-centered teaching philosophy, teaching methods follow the basic principles of the performance in the actual process of teaching teachers to use the language of instruction should pay attention to the following points.

\section{The language combinations presented to student-oriented method}

Classroom teaching is the main front education, modern language teaching presents to play the advantages of modern educational technology; it will be easy to accept a form of abstract concepts and theories to the image presented to the students. At the same time, the language of instruction but also maintain a "cited without hair, jump as too" attitude, inspire students thinking, students struck a chord. To take advantage of a variety of charts, tables, animations, video, audio and other information, as far as possible to provide students with a variety of multi-sensory stimulation: (1) use vivid language to enable students to take the hint; (2) with enlightening teaching language to develop students' thinking ; (3) with contagious MOI open students' hearts.

\section{In principle, the use of language teaching should be in accordance with the needs of various factors, rational choice}

Since the teaching activities, students of different levels, different disciplines property, coupled with the impact of other factors in the teaching, so that teaching language teaching should also be in accordance with the needs of various factors, rational choice, which reflects the layering teaching language. First, in a specific teaching activities, since imparting knowledge attributes, the language of instruction should be properly designed trade-offs, such as the arts and sciences compared to liberal 
arts education activities emphasized the precise language of instruction, clear, vivid, science and engineering disciplines due to the wealthy property logic, so the language of instruction and logical, emphasizing teaching language accurately, refining; second, level differences between students knowledge and age, resulting in student acceptance of teachers 'language are also different, teachers must be based on the students' knowledge level and age and other characteristics, or circumflex tone, full of vivid informative, interesting language, or science, logic, creativity and inspiring strong language. In short, the language depending on the specific circumstances of fine plus discretion, select.

\section{Use of language teaching should be in accordance with the different stages of a reasonable set}

In addition, teachers should reasonably set in the use of the language of instruction, according to the different stages of teaching. As part of the introduction in the classroom, teaching language teaching should be brief and instructive, to stimulate students' thinking, to make it into Consideration; stage in explaining classroom, teachers teaching the language must be lively and humorous, so as to fully mobilize student enthusiasm in the classroom, students produce classroom avoid psychological burnout; summary stage and in the classroom, teaching the use of language should be at a height profile at the same time, emphasis on suspense, students teaching psychological expectations.

\section{Note that each language on language use effective way combination, focused, structured}

Different types of media have different advantages and disadvantages of teaching language and action. Teaching language media diversity requires educators to grasp the advantages and disadvantages of different types of instruction premise, in the actual use of the process to achieve a reasonable, optimal combination, so as to enhance classroom teaching.

Teacher should pay attention to oral language, attention and electro-acoustic language a reasonable match. Suhomlinski said in art education that: "What kind of language teacher cannot be replaced influence the minds of student's tools." [3] Teaching activities in oral language, not only better transmission of information, but also convey emotions better. Teachers use oral language, tone level, a casual look, can give students to remind or implied. Multimedia always just teaching aids, electro-acoustic media can only extend and supplement the process of teaching spoken language, but not all, cannot replace the teacher's spoken language, cannot replace the emotional communication between people. In information technology classroom teaching, teachers should pay more attention to communicate with students, discussed the use of the language of instruction teachers contagious, enhance teacher-student emotional communication; promote teacher-student interaction thinking, let into the computer teaching blunt vitality and affection, so it is more humane and humanistic.

Explore multimedia language use law, students' active thinking habits. Through the development of multimedia silent language use law to help students understand the process of lectures, learning quickly into the state, develop the habit of active thinking. For example: The course explains the process typically includes a general introduction to the concept proposed to explain the content, conclusions, exercise, and several other essential parts. When teachers create multimedia courseware can make this into different sections of color and style templates. Multimedia courseware presentation of the regular use of color and style of the silent language, so that students quickly grasp course explains the law, improve the efficiency of the initiative and lectures.

\section{Conclusions}

The teaching language at Information Age not only includes spoken language teachers use in the classroom activities for use, but also includes multiple languages written language teachers in the teaching activities used, audio language, images and language, which cooperate with each other in the teaching process, the integrated use of language constitutes a form of teaching tools and information transmission carrier. Teaching basic language teaching skills as a teacher, master and use effectively enhance the effect of classroom teaching, to narrow the psychological distance with students, student 
teachers to avoid the psychological rejection and improve efficiency in the classroom, to stimulate students' thinking, and students to produce effective interactive.

To sum up, specifically to grasp the information age, teachers and the use of a combination of language teaching from the following aspects: (1) follow the teaching methods specific requirements. (2) a combination of moderation and pluralism, graphics and sound Mao, creating interesting language environment for learners. (3) Select the language to use to pay attention to each other. In general you want to strive to do: Use clear, concise language, normative science; language presents vivid, enlightening; language interesting, subtle humor.

\section{Acknowledgments}

This paper is one of 2014 Chongqing Education Committee humanities \& social sciences projects, No.: fdyzy2014010 .

\section{References}

[1] Liu Guoqing. On Teaching Language scope and features of existing forms and elements. Journal of Luoyang Normal College, 2000, 19(1): 131.

[2] Song Qirui, Feng Xiancan. Teaching Language Theory. Guangzhou: Guangdong Education Press, 1999.

[3] Sukhomlinskii. Art of Education. Translated by Xiao Yong, Changsha: Hunan Education Press, 1983. 